OPEN ACCESS

Edited by:

Carl James Yeoman,

Montana State University,

United States

Reviewed by:

Raul G. Barletta,

University of Nebraska

Lincoln, United States

Kenneth James Genovese,

United States Department of

Agriculture, Agricultural

Research Service, United States

*Correspondence:

Nejash Abdela

nejash.abdela@gmail.com

Specialty section:

This article was submitted to Veterinary Infectious Diseases,

a section of the journal

Frontiers in Veterinary Science

Received: 09 February 2017

Accepted: 12 June 2017

Published: 28 June 2017

Citation:

Abdela N and Yune N (2017)

Seroprevalence and Distribution of Contagious Bovine Pleuropneumonia in Ethiopia: Update and Critical

Analysis of 20 Years

(1996-2016) Reports.

Front. Vet. Sci. 4:100.

doi: 10.3389/fvets.2017.00100

\section{Seroprevalence and Distribution of Contagious Bovine Pleuropneumonia in Ethiopia: Update and Critical Analysis of 20 Years (1996-2016) Reports}

\author{
Nejash Abdela* and Nesradin Yune \\ School of Veterinary Medicine, College of Agriculture and Veterinary Medicine, Jimma University, Jimma, Ethiopia
}

Contagious bovine pleuropneumonia (CBPP), infectious and highly contagious diseases of cattle in Africa, is the only bacterial disease in the OIE list A diseases. This severe respiratory disease of cattle is the second most important transboundary animal disease in Africa after rinderpest. CBPP is caused by Mycoplasma mycoides subsp. mycoides SC (small colony bovine biotype) and it is endemic disease in many African countries including Ethiopia. This paper systematically reviews prevalence report at herd and individual animal level for the last 20 years (1996-2016) with main aim of making comprehensive document regarding the seroprevalence and distribution of CBPP in Ethiopia. The paper is therefore helpful in knowing the past and current disease status and also to forecast the future and possible prevention option in the country. So far, the seroprevalence that ranges from 0.4 to $96 \%$ was reported from different export quarantine centers and production areas in Ethiopia. The reported seroprevalence is significantly associated with different agro-ecology of the country and the highest was reported from lowland in which $40 \%$ of livestock population was kept. The recent seroprevalence studies report from different areas of the country also indicated as CBPP is posing a major threat to cattle production in many parts of the country, thereby causing considerable economic losses through morbidity and mortality. This disease also causes restriction on the trade of animals and animal products internationally and accounts for a loss of over 8.96 million US dollars per year in Ethiopian situation. Thus, a great attention should be given both at production areas and the quarantine stations as its occurrence may affect the export earnings of the country, thereby threatening the livelihood of pastoralists and national economy of the country.

Keywords: contagious bovine pleuropneumonia, distribution, Ethiopia, seroprevalence, trans-boundary animal disease

\section{INTRODUCTION}

Ethiopia is a resourceful country bestowed with estimated largest livestock population in Africa. The livestock sector has a significant role in socioeconomic activities of the country and contributes much to the national economy (1). The contribution of livestock to the national economy 
particularly with regard to foreign currency earnings is through exportation of live animals, meat, skin, and hides $(2,3)$. However, development of this sector is hampered by different constraints. The most important constraints are widespread endemic diseases including viral, bacterial, and parasitic infestation (4-10). The other important bottleneck for the development of this sector include lack of appropriate disease control policy, lack of appropriate veterinary services, and lack of attention from government $(6-8,10-13)$. Among the health constraints, infectious disease like contagious bovine pleuropneumonia (CBPP) is considered to be one of the most economically important and major problem for Ethiopian livestock development (14-16).

Contagious bovine pleuropneumonia, also known as cattle lung disease, is one of the most important infectious and highly contagious diseases of cattle in Africa (17-19). The causative agent of CBPP is Mycoplasma mycoides subsp. mycoides, SC (small colony, bovine biotype) (20). The Pan African programme for the Control of Epizootics (PACE) identified CBPP as the second most important transboundary disease in Africa, after Rinderpest (21). Following the eradication of rinderpest from Africa, CBPP has become the disease of prime concern in terms of epizootics that affect cattle in the continent (20). It is estimated that annual losses due to CBPP amount to 38.81 million US dollars in 12 endemically infected sub-Saharan African countries (21). On account of its transmissibility and economic impacts, CBPP is now recognized as a priority transboundary disease and has thus been categorized as the only bacterial disease in the OIE list A diseases (22). CBPP is transmitted by direct contact between infectious and susceptible cattle and is characterized by its variable course and insidious nature (23).

The disease affects the respiratory tract of cattle and characterized by fever, anorexia, dyspnea, polypnea, cough, and nasal discharge $(17,24)$. All ages of cattle are susceptible, but young cattle develop joint swelling rather than lung infections. Many cattle show no disease signs despite being infected (25) and chronically infected animals might act as carriers and sources of infections (17).

This respiratory disease is considered as great economic importance to cattle keepers because of its high mortality rate, production loss, increased production cost due to cost of disease control, loss of weight and working ability, delayed marketing, reduced fertility, loss due to quarantine, loss of cattle trade, and reduced investment in livestock production $(21,26)$. Regarding the Ethiopian situation, CBPP has been causing significant economic losses on the livestock sector and the national economy. It accounts for a loss of over 8.96 million US dollars per year (27). Thus, over the last decades, the country has lost a substantial market share and foreign exchange earnings due to frequent bans by the Middle East countries (28).

Recent studies conducted in Western part of Ethiopia (16), Northern Ethiopia (29), Southern Ethiopia (30), Southwest Ethiopia (31), and different regions of the country (32) showed that CBPP is posing a major threat to cattle production in many parts of the country, thereby causing considerable economic losses through morbidity and mortality and demanding for serious attention from the concerned body. Furthermore, CBPP has been reported from different export quarantine centers in the country
(33-35) signifying that CBPP remain a threat to livestock export market and may reduce the investment in livestock production. Studies undertaken so far in Ethiopia reported seroprevalence that range from $0.4 \%$ from export from export quarantine centers $(15,34)$ to $96 \%$ from Western Gojjam $(36)$.

Despite aforementioned situation of CBPP in the country, there is scarcity of well-documented information. Therefore, the main objective of this paper was to make comprehensive document on seroprevalence and distribution of CBPP in the country. The paper systematically reviews prevalence report at herd and individual animal level for the last 20 years (1996-2016) and highlighted prevention options and future prospects.

\section{HISTORICAL PERSPECTIVE AND GENERAL ASPECTS OF CBPP IN ETHIOPIA}

Epizootic diseases have threatened cattle since their domestication. Two of them played a prominent role in the last three centuries, namely rinderpest and CBPP threatening the livelihood of whole populations and hindering international cattle trade. However, while rinderpest has been successfully eradicated worldwide (37), CBPP is still present in many African countries including Ethiopia.

Although its origin is not documented, from a historical perspective CBPP was a disease of Europe and Asia (38). It was known in Europe in 1773 and it reached nearly worldwide distribution in the nineteenth century through the cattle trade (39). Through the application of restrictions to the movement of cattle, as well as test and slaughter policies combined with compensation for livestock keepers, CBPP has been eradicated from Australia, Europe, Asia, and America. However, such policies are difficult to apply in most African countries because of pastoralism, lack of economic resources, and fragmented veterinary services $(40,41)$. As a result, the disease remains endemic in Africa particularly in tropical and subtropical regions (West, Central, East, and parts of Southern Africa) of the continent (20,40). Its incidence began to decline in Africa by the 1970s during the late 1980s and 1990s; however, this disease increased in prevalence in endemic areas and re-emerged in some African and European countries that had been CBPP free (19).

It is a prominent cattle disease in Africa, where outbreaks of the disease reported from 20 countries in 2006, with the highest number of cases in Ethiopia, Angola, and Cameroon (42). Over the last few years, major CBPP epidemics have been experienced in Eastern, Southern, and West Africa. Currently, it affects 27 countries in Africa with an estimated annual cost of US $\$ 2$ billion (43). A total of 2,719 outbreaks were reported in Africa between 1995 and 2002 (21).

Regarding the situation in east Africa in general and Ethiopia in particular, there is a suggestion that CBPP was introduced into East Africa from India by the army of field Marshal Napier when he invaded Ethiopia in 1867-1868 (14). Countries in East Africa reported $66 \%$ of the total outbreaks (58\% in Ethiopia and Tanzania and $8 \%$ in other countries in the region) (21). Ethiopia is one of east African countries in which CBPP is endemically 
maintained all over the country with $25 \%$ morbidity and more than $10 \%$ mortality $(14,21)$. A total of 583 outbreaks of CBPP were reported between 1995 and 2002 in Ethiopia in which highest outbreaks (187) were reported in 1998 (21). In general, CBPP has been causing significant economic losses on the agricultural sector and the national economy of Ethiopia. Over the last decades, the country has lost a substantial market share and foreign exchange earnings due to frequent bans by the Middle East countries (28). It accounts for a loss of over 8.96 million US dollars per year (27).

\section{SEROPREVALENCE OF CBPP AND ITS DISTRIBUTION IN ETHIOPIA}

According to Teklue et al. (29) and Mamo (31), the seroprevalence of CBPP is associated with the agro-ecology, and there is significant difference in different agro-ecology. It was found to occur at high rate, almost two times higher, in wet season of the year as compared with dry season (44). In addition, difference between month of the year has been indicated with highest seropositivity on July (0.7\%) and lowest on June (0.1\%) (15). Furthermore, a significantly higher seroprevalence was found in animals in the lowland than those in the highland and mid highland agro-ecology (31). This is major threat to the country as $40 \%$ of livestock population was kept under the pastoral lowland (45). Ethiopia has diverse agro-climatic conditions that can be broadly divided into highlands (1,500 $\mathrm{m}$ above sea level) $39 \%$ and lowlands (1,500 m below sea level) $61 \%$. The lowlands, which are commonly referred to as "pastoral areas," are found in the Eastern, South-Eastern, and Southern parts of the country. Moreover, Ethiopia is a tropical African country in which mobile pastoralism is dominant in the arid and semi-arid areas in the eastern, northeastern, and southeastern parts of the country (46). This practice facilitates the transmission of the disease from one herd or area to another and the establishment of the disease in the country (47).

Even though there is a paucity of research conducted on CBPP in the country, the disease is widespread and considered as one of the most important cattle diseases and impediments to livestock development in Ethiopia $(20,35,48)$. Studies undertaken on CBPP so far revealed the existence of the disease in different parts of the country with prevalence that range from $0.4 \%$ (from bull at finishing phase for export in East Shewa zone that brought from Borena pastoral area) (15) to $96 \%$ in Western Gojjam (36). The current distribution of CBPP in different areas of Ethiopia is shown in Figure 1.

Gizaw (49) conducted serological study in two zones of the Somali Regional State (Jijiga and Shinille) in six districts. A total of 793 serum samples were tested from 56 herds and reported average seroprevalence of $30.4 \%$ in 17 herds with at least 1 infected animal per herd. The herd level prevalence reported was higher in Shinille zone (35.1\%) than in Jijiga zone $(21.1 \%)$. On the other hand, the individual level seroprevalence of the respective zones was 11.6 and $4.3 \%$, which were much lower than herd prevalence. The highest herd seroprevalence was observed in Mieso (100\%) followed by Qabribeyah (75\%) and Afdem (71.4\%) districts.
The study conducted by Kassaye and Molla (33) examined 3,111 cattle sera by using competitive enzyme-linked immunosorbent assay (c-ELISA) during a period of 2010-2011 and reported a $4 \%$ seroprevalence of CBPP at different export quarantine centers in and around Adama namely, Bekero, Dera, Jogo, and Kedir. The highest seroprevalence was reported from Bekero export quarantine farm (4.7\%) and the lowest from Kedir (2.5\%). Furthermore, they indicated as CBPP threat for Ethiopian livestock export market and a well-established disease in Borana and Bale areas, where the animals originated.

Another seroprevalence study from export quarantine centers by Birhanu (11) investigated CBPP at Adama-Modjo Livestock Export Industry in five Private beef animals' Exporter Enterprises located in and around Adama. This study examined a total of 4,321 apparently healthy bulls for the prevalence of Anti body against CBPP by using 3ABC ELISA from November 2013 to May 2014 and reported the overall seroprevalence of $8.00 \%$. Those bulls included in their seroprevalence investigation were come from Borena, Arsi, and Bale areas. From Borana out of 857 bulls examined, 61 are found to be positive with seroprevalence of $10.4 \%$. On the other hand, among 1,432 bulls originated from Bale, 128 are found to be positive with seroprevalence of $8.90 \%$. Furthermore, the lowest prevalence they report was from those bulls that were originated from Arsi with prevalence of $7.70 \%$ among 2019 bull investigated. Moreover, the highest was reported from Jordan Feedlot (22.7\%) whereas the lowest seroprevalence was reported from Seyoum Feedlot (1.40\%).

Ebisa et al. (30) also conducted seroprevalence study from November 2014 to April 2015 in Amaro special district of SNNP region to determine the seroprevalence of CBPP and to assess the potential risk factors for the occurrence of the disease. In their study, total of 400 sera were examined from 4 peasant associations (Jello, Kelle, Golbe, and Gamule) for the presence of specific antibodies against $M$. mycoides subspecies mycoides small colony type by using c-ELISA. Out of 400 sera examined, 127 animals were appeared to be positive and the overall seroprevalence of CBPP was reported to be $31.8 \%$. Moreover, they have reported the highest CBPP seroprevalence (58\%) from Gamule peasant association and the lowest seroprevalence (7\%) from Jello peasant association of Amaro special district of SNNPR.

Teklue et al. (29) investigated CBPP from December 2012 to May 2013 in the four districts (Alamata, Raya Azebo, Ofla, and Endamehoni) of southern zone of Tigray region, Northern Ethiopia. A total of 384 sera samples examined, 36 sera were test positive to CFT giving an overall prevalence of $11.9 \%$. Moreover, they have reported highest seroprevalence from Alamata district (28\%) and lower 0 (0\%) from Ofla and Endamehoni Districts.

Alemayehu et al. (15) conducted seroprevalence of CBPP for 1 year period from January 2011 to December 2011 by using c-ELISA on 40 batches of bulls admitted in 20 different feedlots facilities. A total of 38,187 apparently health bulls that were originated from Borena pastoral area and are on finishing stage for export in East Shewa zone are included in this study. Out of the total 40 batches tested for the presence of antibodies, 25 (62.5\%) of them contained at least 1 seropositive bull and the overall 


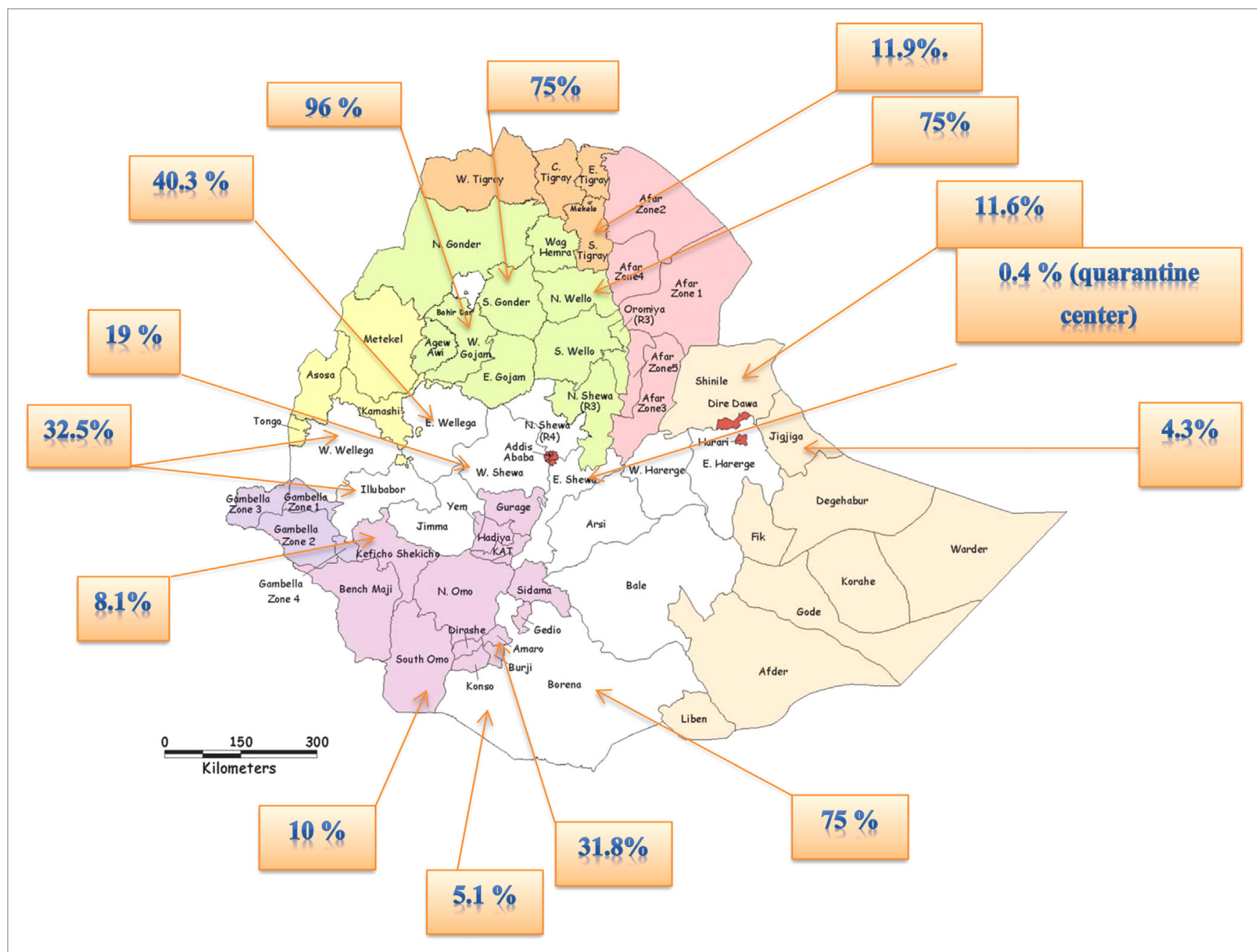

FIGURE 1 | The current distribution of contagious bovine pleuropneumonia in different areas of Ethiopia.

seroprevalence reported was $0.4 \%$ which is relatively lower than the report of other researchers. However, the bulls used for the study was vaccinated against CBPP. At batches level, highest prevalence reported was from feedlots found in Dera, Mekie, Awash 7 killo, Nahmaled, and Adami Tulu sites (100\%) whereas the lowest was recorded in feedlots found in Modjo and Awash Melkasa sites. Furthermore, at individual animal level, the highest seropositivity was indicated in Mekie (1.1\%), and the lowest was indicated in Moddjo site (0.0\%). Moreover, this study reported the highest CBPP prevalence in herd size $>1,000$ which is $93.8 \%$ and concluded that number of seropositive animals increases as the herd size increases.

Another seroprevalences study conducted by Dele et al. (34) in cattle originated from Borana at export quarantine centers in Adama revealed $0.4 \%$ prevalence out of 3,777 cattle investigated. The two studies $(15,34)$ on the animal from the same origin revealed the same result. However, the later one is conducted on apparently healthy animals intended for export to Egypt market that are not vaccinated for the CBPP. Moreover, another serological study in Borena zone revealed 5.1\% prevalence by Issa (50) and $74 \%$ prevalence by Roger and Yigezu (51).
Atnafie et al. (35) conducted seroprevalence study from October 2014 to April 2015 to determine seroprevalence of CBPP among apparently healthy bulls to be slaughtered at selected abattoirs in Bishoftu and from export oriented feedlots around Adama. Total of 384 animals from abattoirs and 1,086 animals from feedlots were examined for the presence of antibody against CBPP using c-ELISA and about 30 (7.8\%) animals from abattoirs and 65 animals (5.9\%) from feedlots were found to be positive.

Furthermore, recently Daniel et al. (16) conducted seroprevalence study on CBPP from November 2013 to March 2014 in selected districts of three Western Oromia Zones (Western Shoa, Horro Guduru Wollegga, and Eastern Wollegga). In their study, total of 386 sera were examined for the presence of specific antibodies against Mycoplasma mycoidesmycoides small colony (MmmSC) by using a c-ELISA and reported an overall seroprevalence of $28.5 \%$. Moreover, they indicated highest seroprevalence $(40.3 \%)$ in Gobbu Sayyo district of Eastern Wollegga Zone, while the lowest seroprevalence (5.7\%) in Horro district of Horro Guduru Wollegga Zone. The seroprevalence in Bako Tibbo of Western Shoa zone was $19.0 \%$. 
Another more recent seroprevalence study conducted in southwest Ethiopia by Mamo (31) investigated seroprevalence and associated risk factor from October 2015 to August 2016 by using c-ELISA. The total of 384 cattle in Gimbo district of Keffa zone Southern nation's nationalities and people's regional sate of Ethiopia was examined. The overall seroprevalence reported was $8.1 \%$ with the highest seroprevalence from lowland and followed by mid highland.

In general at the country level, CBPP seroprevalence studies have been conducted in different localities of the country. However, there is a great variation of reports from different areas this variation in the prevalence reported could be due to difference in agro-ecological system, animal management, production system, population density, and the types of tests used to evaluate the seroprevalence $(16,30)$. Bellini et al. (52) showed the specificity of CFT (threshold $+1: 10$ ) to be $98 \%$ and sensitivity to be
63.79\%. A c-ELISA test has undergone evaluation and is possible to apply at animal level (for interpretation) and compared with CF test, the c-ELISA has equal sensitivity and greater specificity. The c-ELISA is an individual test but you can aggregate the results and therefore interpret it at herd, and it is easier to perform than the CF test but its performance characteristics have not yet been fully assessed (22). The validation c-ELISA tests that have been carried out in several African and European countries have indicated true specificity of the c-ELISA to be at least $99.9 \%$ and the sensitivity of the c-ELISA and the CF test are similar (22). The antigen in CFT is a suspension of MmmSC, previously checkerboard titrated and used at a dose of two complement fixing units. A c-ELISA is based on a monoclonal anti-MmmSC antibody, named Mab 117/5 (22).

The seroprevalence report of CBPP from 1996 to 2016 from different areas of Ethiopia along with its distribution is summarized in Table 1 .

TABLE 1 | Seroprevalence reports of contagious bovine pleuropneumonia from different locations in Ethiopia from 1996 to 2016.

\begin{tabular}{|c|c|c|c|c|c|}
\hline Reference & Study duration & Diagnostic test used & Location (study area) & Sample size & Prevalence (\%) \\
\hline \multirow[t]{3}{*}{$(51)$} & November 1995 to May 1996 & CFT & North Omo & 374 & 29 \\
\hline & & & Konso S.D. & 59 & 46 \\
\hline & & & Dirashe S.D. & 70 & 32 \\
\hline \multirow[t]{7}{*}{$(36)$} & 1996 & CFT & Western Wellega & 360 & 75 \\
\hline & & & Western Gojam & 80 & 96 \\
\hline & & & Southern Gondar & 60 & 75 \\
\hline & & & Northern Wello & 60 & 75 \\
\hline & & & Northern Shewa & 100 & 100 \\
\hline & & & Southern Tigray & 20 & 54 \\
\hline & & & Borena & 370 & 75 \\
\hline (53) & November 1996 to May 1997 & $\mathrm{CFT}$ & Western Ethiopia (Ilu Ababor and Wellega) & & 32.5 \\
\hline (54) & 1996-1997 & $\begin{array}{l}\text { CFT and competitive enzyme-linked } \\
\text { immunosorbent assay (c-ELISA) }\end{array}$ & Western Gojjam & 2,140 & 9.1 \\
\hline$(55)$ & November 2000 to April 2001 & CFT & West Wellega & 50 herds & 4 (herd Prevalence) \\
\hline \multirow[t]{2}{*}{ (49) } & 2003-2004 & c-ELISA & Jijiga zone & 140 & 4.3 \\
\hline & & & Shinille zone & 653 & 11.6 \\
\hline$(50)$ & 2003-2004 & ELISA and CFT & Oromia (Borena zone) & & 5.1 \\
\hline (33) & October 2010 to March 2011 & c-ELISA & Quarantine centers in and around Adama & 3,111 & 4 \\
\hline (34) & & $\mathrm{CFT}$ & Quarantine centers in and around Adama & 3,777 & 0.4 \\
\hline (29) & December 2012 to May 2013 & $\mathrm{CFT}$ & Tigray (southern zone) & 384 & 11.9 \\
\hline$(11)$ & November 2013 to May 2014 & 3ABC ELISA & Adama-Modjo Livestock Export Industry & 4,321 & 8.00 \\
\hline$(15)$ & January 2011 to December 2011 & c-ELISA & $\begin{array}{l}\text { Feed lot at East Shewa zone } \\
\text { (animal originated from Borena zone) }\end{array}$ & 38,187 & 0.4 \\
\hline$(44)$ & - & c-ELISA & Dassenech district of South Omo Zone & 68 & 10 \\
\hline (30) & November 2014 to April 2015 & C-ELISA & SNNP (Amaro district) & 400 & 31.8 \\
\hline \multirow[t]{2}{*}{ (35) } & October 2014 to April 2015 & c-ELISA & Bishoftu & 384 & 7.8 \\
\hline & & & Adama & 1,086 & 5.9 \\
\hline \multirow[t]{3}{*}{$(16)$} & November 2013 to March 2014 & c-ELISA & Western Shoa & 100 & 19 \\
\hline & & & Horro Guduru Wollegga & 70 & 5.7 \\
\hline & & & Eastern Wollegga & 216 & 40.3 \\
\hline \multirow[t]{2}{*}{ (31) } & October 2015 to August 2016 & c-ELISA & SNNP & 384 & 8.1 \\
\hline & & & Kefa Zone & & \\
\hline
\end{tabular}




\section{PREVENTION AND FUTURE PROSPECTS OF CBPP}

Transmission of CBPP requires direct contact between infectious and susceptible cattle (23). Therefore, strategies for CBPP control and eradication can rely on four broad approaches that aim to reduce effective animal contact: stamping out, cattle movement control, vaccination, and antimicrobial treatment $(21,56-58)$.

Stamping out involves slaughter of all CBPP-infected and in-contact cattle. This approach was used in combination with movement restriction to eradicate CBPP from the UK, North America, and Western Europe (59). Stamping out has been termed as the simplest and surest way to control and eradicate CBPP. However, stamping out has far reaching socioeconomic effects (60). Consequently, it is recommended that stamping out should be a strategy of last resort to be used in critical epidemiological situations such as in the case of outbreaks in a free area or the surveillance zone (of a sanitary cordon) or on major trade routes. It can also be introduced at a later stage of the campaign after substantial reduction of CBPP incidence such that the incidence is approaching $0(61)$.

The application of movement restrictions and stamping out do not appear practically feasible to be applied in sub-Saharan Africa due to pastoral nature of cattle husbandry and resource limitations. Therefore, the levels of movement control consistent with sustainable pastoral livelihoods are unlikely to have a major impact on CBPP prevalence in the future (23). Thus, the control of CBPP has relied on preventive immunoprophylaxis using liveattenuated cultures of the causative agent.

The OIE recommends $\mathrm{T} 1$ vaccine strain for vaccination against CBPP. It is generally accepted that the protection offered by the vaccine wanes after 12 months (62) but may last for more than 1 year (63). The vaccine is sufficiently avirulent but can cause severe post-vaccinal adverse reactions in some breeds (64). In general, the successful eradication of CBPP can eliminate any future control cost of vaccination, treatment, quarantine, and movement control, which benefit producers and the nation. Control of CBPP is, therefore, important as a way to salvage the losses and increase the incomes of cattle owners (21).

All effective CBPP vaccines have been based upon live versions of the disease causing MmmSC, either attenuated or not. Currently, the only vaccines in use are live vaccine derived from the T1 strain (T1/44 and T1SR) of live-attenuated M. mycoides subsp. mycoides SC and attenuated through repeated passage in embryonated eggs before production in artificial growth media. Unfortunately, these vaccines are characterized by poor and variable efficacy, with only between 30 and $60 \%$ of vaccinated animals being protected. In some situations, the T1/44 vaccine induces a good immunity, especially when herds are revaccinated

\section{REFERENCES}

1. CSA. Federal Democratic Republic of Ethiopia. Central Statistical Agency. Agricultural Sample Survey, Volume II, Report on Livestock and Livestock Characteristics. Statistical Bulletin 583. Addis Ababa: CSA (2016). annually, in which case the level of protection exceeds $85 \%$. Induced immunity is short lived, particularly for the T1SR strain, requiring revaccination at least on a yearly basis. Either systemic or local adverse reactions are common, particularly for the T1/44 strain. Within 2-4 weeks following injection, an invading edema develops known as the "Willems" reaction. The incidence of these reactions varies from one area to another. The reversion to virulence of the T1/44 vaccine has also been observed when it was serially passaged by endobronchial intubation resulting in the development of lesions of CBPP in animals that were infectious to in-contact animals. This suggests that animals given the currently used vaccines (T1/44 and T1SR) subcutaneously could be reservoirs for $\mathrm{MmmSC}$ and infect other animals in areas previously free of CBPP (65).

\section{CONCLUSION}

Contagious bovine pleuropneumonia is economically important infectious and highly contagious disease of cattle characterized by variable course and insidious nature. The recent seroprevalence studies from different areas of Ethiopia witnessed as this severe respiratory disease is posing a major threat to livestock industry of the country. At the country level, seroprevalence studies have been conducted in different localities of the country both at production area and the quarantine stations. However, there is a great variation of reports from different areas that range from 0.4 to $96 \%$. Furthermore, the reported seroprevalence is significantly associated with agro-ecology of the country and the highest was reported from lowland in which $40 \%$ of livestock population of the country was kept. Thus, it requires great attention both at production area and the quarantine stations as its occurrence may cause restriction on the trade of animals and animal products internationally, affecting the export earnings of the country, thereby threatening the livelihood of pastoralists and national economy. Moreover, effective vaccination policy needs to be considered as it is the only realistic method of choice for control of CBPP in the country with movement control if possible.

\section{AUTHOR CONTRIBUTIONS}

All authors listed have made substantial, direct, and intellectual contribution to the work and approved it for publication.

\section{ACKNOWLEDGMENTS}

Words are inadequate to express my deep sense of indebtedness to my sister Nebati Abdela for her encouragements and continuous support. Next I would like to thanks Jimma University for facility support and Internet access.

2. Ayele SW, Assegid MA, Jabbar MM, Belachew H. Livestock Marketing in Ethiopia: A Review of Structure, Performance and Developing Initiatives, Working Paper No. 52. Addis Ababa (2003). p. 1-4.

3. FAO. Ethiopia FAO's Information System on Water and Agriculture. Italy (2005). Available from: http://www.Fao.org 
4. Abdela N, Bekele T. Bovine theileriosis and its control: a review. Adv Biol Res (2016) 10(4):200-12. doi:10.5829/idosi.abr.2016.10.4.103107

5. Abdela N, Jilo K. Bovine babesiosis and its current status in Ethiopia: a systematic review. Adv Biol Res (2016) 10(3):138-46. doi:10.5829/idosi. abr.2016.10.3.10398

6. Abdela N. Important cattle ticks and tick born haemoparasitic disease in Ethiopia: a review. Acta Parasitol Glob (2016) 7(1):12-20. doi:10.5829/idosi. apg.2016.7.1.102140

7. Abdela N, Midekso B, Jabir J, Abdela W. Knowledge, attitudes and practices towards rabies in Dedo district of Jimma Zone, Southwestern Ethiopia: community based cross-sectional study. Int J Med Med Sci (2017) 9(5):61-71.

8. Abdela N. Sero-prevalence, risk factors and distribution of foot and mouth disease in Ethiopia. Acta Trop (2017) 169:125-32. doi:10.1016/j. actatropica.2017.02.017

9. Abdela N, Teshome E, Hassan A, Deressa FB. Prevalence and associated risk factors of equine wound in and around Asella town, South Eastern Ethiopia. J Vet Med Anim Health (2017) 9(4):63-71. doi:10.5897/JVMAH2017.0551

10. Yune N, Abdela N. Epidemiology and economic importance of sheep and goat pox: a review on past and current aspects. J Vet Sci Technol (2017) 8(2):1-5. doi:10.4172/2157-7579.1000430

11. Birhanu T. Prevalence of the major infectious animal diseases affecting livestock trade industry in Ethiopia. J Biol Agr Health (2014) 4(17):62-76.

12. Jilo K, Abdela N, Adem A. Insufficient veterinary service as a major constraints in pastoral area of Ethiopia: a review. J Biol Agr Health (2016) 6(9):94-101.

13. Abdela N, Deressa FB, Hassan A, Teshome E. Study on prevalence of indigestible foreign bodies in the rumen and reticulum of sheep slaughtered at Jimma municipal abattoir, Southwestern Ethiopia. Glob J Med Res (2017) $17(2): 27-34$.

14. Masiga WN, Domenech J, Windsor RS. Manifestation and epidemiology of contagious bovine pleuropneumonia in Africa. Rev Sci Tech (1996) 15(4):1283-308.

15. Alemayehu G, Leta S, Hailu B. Sero-prevalence of contagious bovine pleuropneumonia (CBPP) in bulls originated from Borena pastoral area of Southern Ethiopia. Trop Anim Healt prod (2015) 47(5):983-7. doi:10.1007/ s11250-015-0820-9

16. Daniel G, Abdurahaman M, Tuli G, Deresa B. Contagious bovine pleuropneumonia: seroprevalence and risk factors in Western Oromia, Ethiopia. Onderstepoort J Vet Res (2016) 83(1):1-5. doi:10.4102/ojvr.v83i1.958

17. Schnee C, Heller M, Jores J, Tomaso H, Neubauer H. Assessment of a novel multiplex real-time PCR assay for the detection of the CBPP agent Mycoplasma mycoides subsp. mycoides SC through experimental infection in cattle. BMC Vet Res (2011) 7(1):1. doi:10.1186/1746-6148-7-47

18. Tardy F, Gaurivaud P, Manso-Silván L, Thiaucourt F, Pellet MP, Mercier P, et al. Extended surveillance for CBPP in a free country: challenges and solutions regarding the potential caprine reservoir. Prev Vet Med (2011) 101(1):89-95. doi:10.1016/j.prevetmed.2011.04.017

19. CFSPH (Center for Food Security and Public Health). Contagious Bovine Pleuropneumonia. Ames, IA: Iowa State University (2015).

20. Amanfu W. Contagious bovine pleuropneumonia (lungsickness) in Africa. Onderstepoort J Vet Res (2009) 76:13-7. doi:10.4102/ojvr.v76i1.55

21. Tambi NE, Maina WO, Ndi C. An estimation of the economic impact of contagious bovine pleuropneumonia in Africa. Rev Sci Tech (2006) 25(3):999-1011.

22. Office Internationale des Epizooties (OIE). Manual of Standards for Diagnostic Tests and Vaccines. 4th ed. Paris: OIE (2000). p. 123-33.

23. Mariner JC, McDermott J, Heesterbeek JAP, Thomson G, Martin SW. A model of contagious bovine pleuropneumonia transmission dynamics in East Africa. Prev Vet Med (2006) 73(1):55-74. doi:10.1016/j.prevetmed.2005. 09.001

24. Schubert E, Sachse K, Jores J, Heller M. Serological testing of cattle experimentally infected with Mycoplasma mycoides subsp. mycoides small colony using four different tests reveals a variety of seroconversion patterns. BMC Vet Res (2011) 7:72. doi:10.1186/1746-6148-7-72

25. Scacchia M, Tjipura-Zaire G, Lelli R, Sacchini F, Pini A. Contagious bovine pleuropneumonia: humoral and pathological events in cattle infected by endotracheal intubation or by exposure to infected animals. Vet Ital (2011) 47(4):407-13.

26. Radostits OM, Gay CC, Hinchcliff KW, Constable PD. A Textbook of the Disease of Cattle, Sheep, Pigs, Goats and Horses. 10th ed. Spain: Sounders Elsevier (2007). p. 1125-31.
27. Laval G. Cost Analysis of Contagious Bovine Pleuropneumonia in Ethiopia. MSc Thesis, Claude Bernard University, Lyon (1999). Available from: https:// cgspace.cgiar.org/handle/10568/79497

28. Belachew H, Jemberu E. Challenges and opportunities of livestock marketing in Ethiopia. In: Yilma J, Getachew G, editors. Proceedings of the 10th Annual Conference of the Ethiopian Society of Animal Production (ESAP); 2002 Aug 24-26; Addis Ababa, Ethiopia (2003). p. 27.

29. Teklue T, Tesfay T, Nirayo T, Hailu B, Wayu S, Atsbha T. Epidemiological status of contagious bovine pleuropneumonia in southern zone of Tigray regions, Northern Ethiopia. Anim Vet Sci (2015) 3(1):32-6. doi:10.11648/j. avs.20150301.17

30. Ebisa T, Hirpa H, Aklilu F. Study on seroprevalence and risk factors contagious bovine pleuropneumonia in southern nation and nationality people of Ethiopia regional state in Amaro special district. Sci Technol Arts Res J (2015) 4(4):106-12. doi:10.4314/star.v4i4.15

31. Mamo Y. Seroprevalence and Associated Risk Factor of Contagious Bovine Pleuropneumonia in Gimbo District Keffa Zone Southwest Ethiopia. MSc Thesis, College of Agriculture and Veterinary Medicine, Jimma University, Jimma (2016).

32. NAHRC. Report on CBPP Study in Ethiopia. Serosurveillance Results. Sebeta: National Animal Health Research Centre Ethiopian Agricultural Research Organization (EARO) (2000).

33. Kassaye D, Molla W. Seroprevalence of contagious bovine pleuropneumonia at export quarantine centers in and around Adama, Ethiopia. Trop Anim Heal Prod (2013) 45(1):275-9. doi:10.1007/s11250-012-0212-3

34. Dele E, Afera B, Kebede E, Awol N, Hadush B. Seroprevalence of trade hampering livestock diseases in animals originated from Borana at export quarantine centers in Adama, Central Ethiopia. Afr J Bas Appl Sci (2014) 6(2):30-6.

35. Atnafie B, Goba H, Sorri H, Kasaye S. Sero-prevalence of contagious bovine pleuropneumonia in abattoirs at Bishoftu and export oriented feedlots around Adama. Glob Vet (2015) 15(3):321-4.

36. Yigezu LM, Roger F. CBPP European Union Project Component 2: Improvement of Diagnostic Methods Competitive ELISA Kit Assessment Report of the Second Semester Year 2. Ethiopia: National Veterinary Institute (1997).

37. Roeder PL. Rinderpest: the end of cattle plague. Prev Vet Med (2011) 102:98-106. doi:10.1016/j.prevetmed.2011.04.004

38. Windsor RS. The eradication of contagious bovine pleuropneumonia from South Western Africa: a plan for action. Ann N Y Acad Sci (2000) 916:326-32. doi:10.1111/j.1749-6632.2000.tb05309.x

39. Dupuy V, Manso-Silván L, Barbe V, Thebault P, Dordet-Frisoni E, Citti C, et al. Evolutionary history of contagious bovine pleuropneumonia using next generation sequencing of Mycoplasma mycoides subsp. mycoides "Small Colony”. PLoS One (2012) 7(10):e46821. doi:10.1371/journal.pone.0046821

40. Neiman M, Hamsten C, Schwenk JM, Bolske G, Persson A. Multiplex screening of surface proteins from Mycoplasma mycoides subsp. mycoides small colony for an antigen cocktail enzyme-linked immunosorbent assay. Clin Vaccine Immunol (2009) 16(11):1665-74. doi:10.1128/CVI.00223-09

41. Sacchini F, Luciani M, Salini R, Scacchia M, Pini A, Lelli R, et al. Plasma levels of TNF- $\alpha$, IFN- $\gamma$, IL- 4 and IL-10 during a course of experimental contagious bovine pleuropneumonia. BMC Vet Res (2012) 8:44. doi:10.1186/ 1746-6148-8-44

42. Nicholas R, Ayling R, McAuliffe L. Mycoplasma Diseases of Ruminants. Kings Lynn, Norfolk: CAB International, Biddles Ltd (2008). p. 69-97.

43. Otte MJ, Nugent R, McLeod A. Transboundery Animal Diseases: Assessment of Socio-Economic Impacts and Institutional Responses, Livestock Policy Discussion Paper No. 9. Rome: Food and Agriculture Organization Livestock Information and Policy Branch, AGAL (2004).

44. Molla B, Delil F. Mapping of major diseases and devising prevention and control regimen to common diseases in cattle and shoats in Dassenech district of South Omo Zone, South-Western Ethiopia. Trop Anim Heal Prod (2015) 47(1):45-51. doi:10.1007/s11250-014-0681-7

45. CSA. Report on Monthly Average Retail Prices of Goods and Services in Rural Areas by Killil and Zone Statistical Bulletin. Addis Ababa: CSA (2000). $268 \mathrm{p}$.

46. Tegegne A, Mengistie T, Desalew T, Teka W, Dejen E. Transhumance Cattle Production System in North Gondar, Amhara Region, Ethiopia: Is It Sustainable? Improving Productivity and Market Success (IPMS) of Ethiopian Farmers Project. Addis Ababa: International Livestock Research Institute (ILRI) (2009). 
47. Ezanno P, Lesnoff M. A metapopulation model for the spread and persistence of contagious bovine pleuropneumonia (CBPP) in African sedentary mixed crop-livestock systems. J Theor Biol (2009) 256:493-503. doi:10.1016/j. jtbi.2008.10.001

48. Ministry of Agriculture (MOA). Monthly Animal Health Status Report. Addis Ababa: Ministry of Agriculture Veterinary Services, Epidemiology Unit (2003).

49. Gizaw MM. Serological, Clinical and Participatory Epidemiological Survey of Contagious Bovine Pleuropneumonia in Somali Region. MSc Thesis, Addis Ababa University, Ethiopia (2016).

50. Issa A. Epidemiological Study of Contagious Bovine Pleuropneumonia in Borana Pastoral Areas Using Complement Fixation Test and Competitive Enzyme-Linked Immunosorbent Assay. MSc Thesis, Addis Ababa University, Addis ababa (2004).

51. Roger F, Yigezu L. The Situation of CBPP in Ethiopia. Ethiopia: CIRAD-EMVT, National Veterinary Institute (1995).

52. Bellini S, Giovannini A, Di Francesco C, Tittarelli M, Caporale V. Sensitivity and specificity of serological and bacteriological tests for contagious bovine pleuropneumonia. Rev Sci Tech (1998) 17:654-70. doi:10.20506/rst.17.3. 1124

53. Desta B. Sero-Epidemiological Investigation of CBPP in Ilu Ababor and Wellega (Western Ethiopia). Thesis for Degree of Doctor of Veterinary Medicine, Faculty of Veterinary Medicine, University of Addis Ababa, Addis Ababa (1998).

54. Gashaw T. Epidemiological Survey of CBPP in Awi and Western Gojjam Zone of Amhara Region and Comparison of CFT and c-ELISA for the Diagnosis of CBPP. Thesis for Degree of Master of Veterinary Epidemiology, Faculty of Veterinary Medicine, Addis Ababa University and Freie Universität, Berlin (1998).

55. Regassa F. Herd Prevalence of Contagious Bovine Pleuropneumonia (CBPP), Bovine Tuberculosis and Dictyocaulosis in Bodji woreda, West Wellega. DVM Thesis, Addis Ababa University, Faculty of Veterinary Medicine, Debre Zeit (2001).

56. Aliyu M, Obi T, Egwu G. Prevalence of contagious bovine pleuropneumonia (CBPP) in northern Nigeria. Prev Vet Med (2000) 47:263-9. doi:10.1016/ S0167-5877(00)00170-7

57. Kusiluka LJM, Sudi FF. Review of successes and failures of contagious bovine pleuropneumonia control strategies in Tanzania. Prev Vet Med (2003) 59:113-23. doi:10.1016/S0167-5877(03)00087-4
58. Muuka G, Songolo N, Kabilika S, Hangombe BM, Nalubamba KS, Muma JB. Challenges of controlling contagious bovine pleuropneumonia in sub-Saharan Africa: a Zambian perspective. Trop Anim Heal Prod (2012) 45:9-15. doi:10.1007/s11250-012-0235-9

59. Fisher J. To kill or not to kill: the eradication of contagious bovine pleuropneumonia in Western Europe. Med Hist (2003) 47:314-31.

60. Kairu-Wanyoike SW, Kiara H, Heffernan C, Kaitibie S, Gitau GK, McKeever D, et al. Control of contagious bovine pleuropneumonia: knowledge, attitudes, perceptions and practices in Narok district of Kenya. Prev Vet Med (2014) 115(3):143-56. doi:10.1016/j.prevetmed.2014.03.029

61. FAO. Prevention and control of transboundary diseases. Report of Expert Consultation on the Emergency Prevention System (EMPRES) for Transboundary Animal and Plant Pests and Diseases (Livestock Diseases Programme) Including the Blueprint for Global Rinderpest Eradication; 1996 July 24-26, Rome, Italy. Rome: FAO (1997).

62. Wesonga HO, Thiaucourt F. Experimental studies on the efficacy of T1sr and T1/44 vaccine strains of Mycoplasma mycoides subspecies mycoides (Small Colony) against a field isolate causing contagious bovine pleuropneumonia in Kenya, effect of revaccination. Res Vet Sci (2000) 93(2011):568-73.

63. Nkando I, Ndinda J, Kuria J, Naessens J, Mbithi F, Schnier C, et al. Efficacy of two vaccine formulations against contagious bovine pleuropneumonia (CBPP) in Kenyan indigenous cattle. Res Vet Sci (2012) 93(2):568-73. doi:10.1016/j.rvsc.2011.08.020

64. Teshale S. Contagious Bovine Pleuro-pneumonia (CBPP). Post-vaccinal Complication in Ethiopia. Bull Anim Health Prod Afr (2005) 53:242-50.

65. Constable PD, Hinchcliff KW, Done SH, Gruenberg W. Veterinary Medicine: A Textbook of the Diseases of Cattle, Horses, Sheep, Pigs and Goats. China: Elsevier Health Sciences (2017). p. 925-32.

Conflict of Interest Statement: The authors declare that the research was conducted in the absence of any commercial or financial relationships that could be construed as a potential conflict of interest.

Copyright (c) 2017 Abdela and Yune. This is an open-access article distributed under the terms of the Creative Commons Attribution License (CC BY). The use, distribution or reproduction in other forums is permitted, provided the original author $(s)$ or licensor are credited and that the original publication in this journal is cited, in accordance with accepted academic practice. No use, distribution or reproduction is permitted which does not comply with these terms. 